\title{
BMC
}

Research Notes

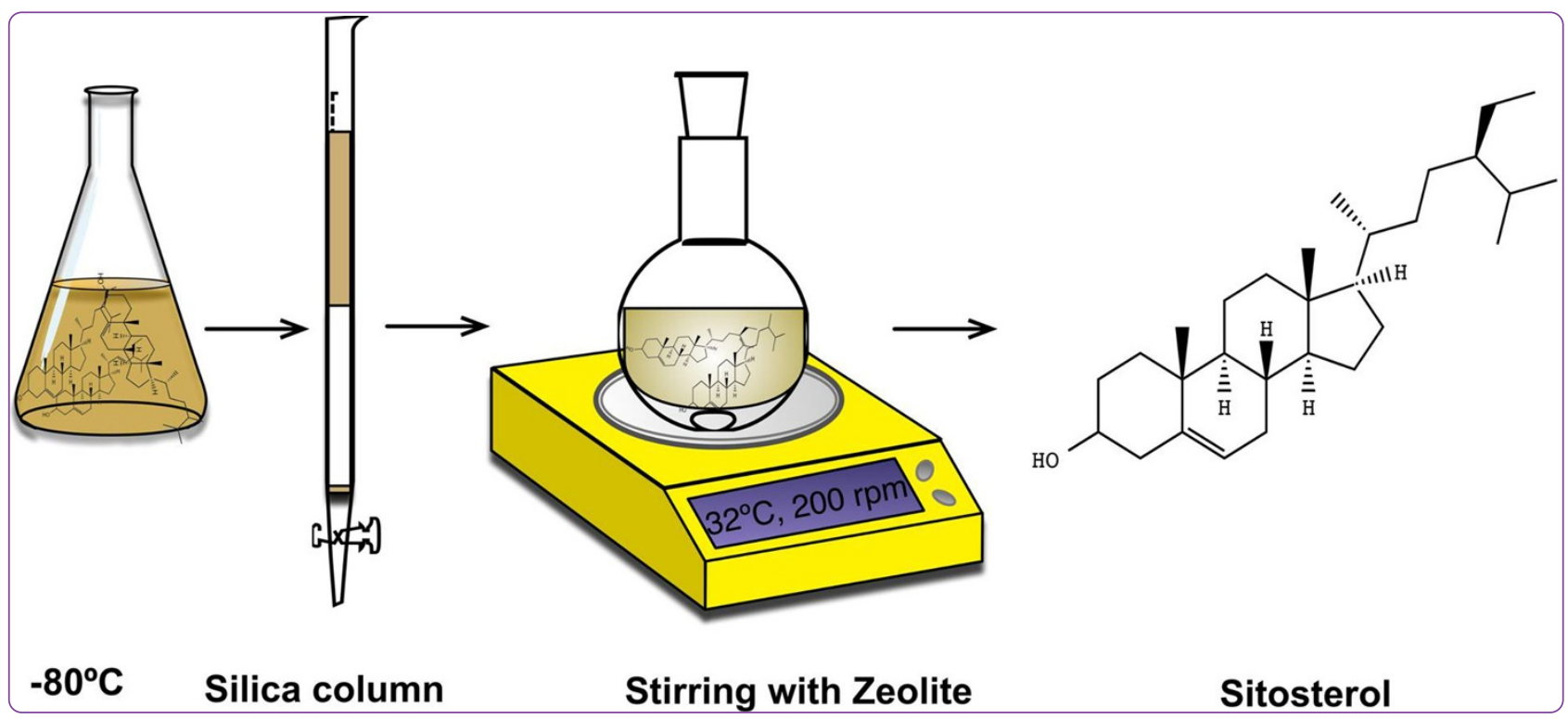

\section{Rapid purification of gram quantities of $\beta$-sitosterol from a commercial phytosterol mixture}

Srividya et al. 


\title{
Rapid purification of gram quantities of $\beta$-sitosterol from a commercial phytosterol mixture
}

Narayanan Srividya, Deanna Brooke Heidorn and Bernd Markus Lange*

\begin{abstract}
Background: $\beta$-Sitosterol, a plant sterol or phytosterol, has commercial uses in the nutraceutical and pharmaceutical industries, but is also employed frequently in biological research. Phytosterols always accumulate as mixtures, and obtaining highly pure $\beta$-sitosterol in larger quantities for biological assays has been a challenge.

Findings: An improved method for the rapid purification of $\beta$-sitosterol from a commercial phytosterol extract is presented. Fractional crystallization of soybean oil yielded a soluble and an insoluble fraction. $\beta$-Sitosterol was purified by silica gel and $\mathrm{Na}-\mathrm{Y}$ zeolite chromatography.
\end{abstract}

Conclusion: The rapid and cost effective three-step purification described here afforded $\beta$-sitosterol in gram quantities with high purity (>92\%) and yield (>22\%).

Keywords: $\beta$-Sitosterol, Purification, Fractional crystallization, Chromatography, Phytosterol, Zeolite

\section{Findings}

\section{Background}

Plant sterols, also referred to as phytosterols, are important structural components of the plasma membrane and are involved in the regulation of various developmental processes, including those mediated by lipid hormones [1-3]. Phytosterols have been used successfully and safely for several decades to lower plasma cholesterol levels, and many margarines, butters, breakfast cereals and spreads are now enriched with plant-derived sterols and their esters $[4,5]$. While considerable progress has been made with obtaining specific phytosterols in pure form, the costs are still very high when larger amounts of pure sterols are required for structure-function studies in the nutritional, pharmaceutical and plant biology fields.

Two general strategies for obtaining gram quantities of individual phytosterols have been pursued. Stigmasterol 1, the most accessible and least expensive phytosterol, can be converted to $\beta$-sitosterol 2, a phytosterol commonly used as a model for this class of plant metabolites, by selective hydrogenation or reduction of the $\Delta^{22-23}$ alkene,

\footnotetext{
* Correspondence: lange-m@wsu.edu

Institute of Biological Chemistry and M.J. Murdock Metabolomics Laboratory, Washington State University, Pullman, WA 99164, USA
}

while protecting the $\Delta^{5-6}$ double bond (Figure 1) [6-8]. Even more cost-effective is the isolation of $\beta$-sitosterol from vegetable oils, but obtaining pure metabolites from mixtures containing structurally related phytosterols has been challenging. The simplest isolation approach is based on a series of crystallizations, but the purity of $\mathbf{2}$ is maximally in the $70 \%$ range [6,9-11]. Further purification to $>90 \%$ purity can be achieved with chromatography over silica gel or $\mathrm{Na}-\mathrm{Y}$ zeolite, but these protocols require repeated, time-consuming cycles of column purification [12-15]. Here we report a facile and rapid method that combines silica gel and Na-Y zeolite chromatography to afford 2 from a vegetable oil-derived phytosterol mixture at high yield (22.5\%) and purity (94.2\%).

\section{Materials}

Crude soybean oil extract (termed "> 40\% sitosterol"; S5753) was obtained from Sigma-Aldrich (St. Louis, $\mathrm{MO}$ ). Solvents (acetone, chloroform, diethyl ether, ethanol, ethyl acetate, hexane, and toluene) were purchased from Fisher Scientific (Waltham, MA). Silica gel for column chromatography (type $60 \AA$; 100-200 mesh, 75$150 \mu \mathrm{m}$ particle size) was obtained from Mallinckrodt (St. Louis, MO). Na-Y zeolite was bought from SigmaAldrich (St. Louis, MO) and activated using a Vulcan 


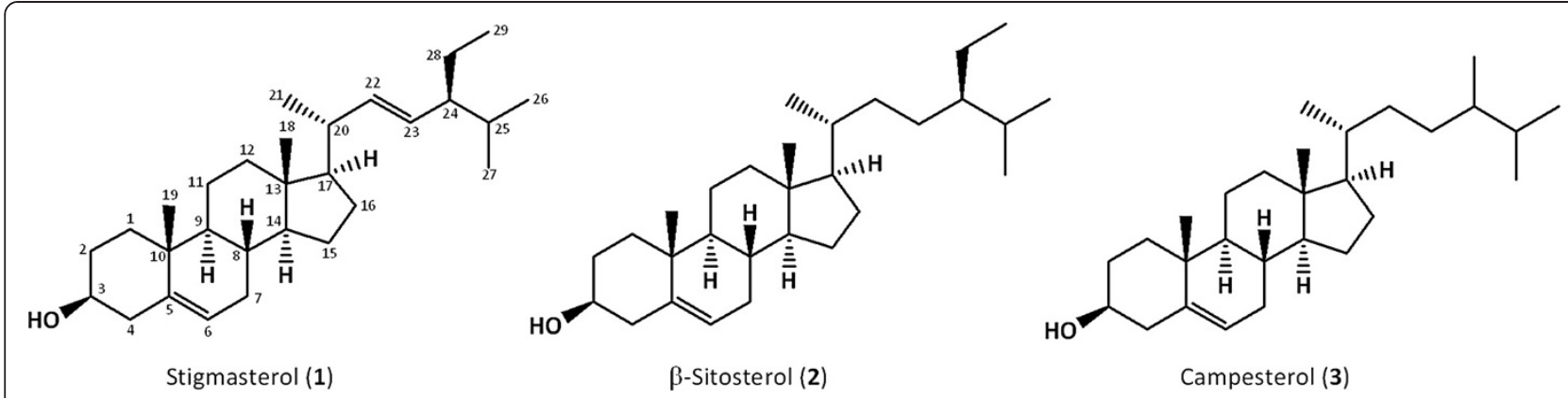

Figure 1 Structures of phytosterols. Common numbering of carbon atoms shown for stigmasterol (1).

3-130 bench top furnace at $500^{\circ} \mathrm{C}$ for $18 \mathrm{~h}$ before use. The stirring speed for batch incubations of $\mathrm{Na}-\mathrm{Y}$ zeolite with phytosterol mixtures was controlled using a PCT900 tachometer (General Tools, New York, NY) so that consistent but slow stirring occurred. Faster stirring speeds led to undesirably high concentrations of campesterol in solution. The Na-Y zeolite was reactivated by furnace heating as above.

\section{Results and discussion}

Fractional crystallization has been used by various groups to obtain a solid $(S)$ and a liquid $(\boldsymbol{L})$ phytosterol fraction, of which only the $\boldsymbol{L}$ fraction (fairly low phytosterol content but with few other contaminants) was further processed. The phytosterol-rich $S$ fraction contained high amounts of $\mathbf{1}$, which was very difficult to remove when $\mathbf{2}$ was the primary target, and was thus discarded [6,9-11]. To avoid substantial losses of 2 , we first tested several solvents for obtaining an $\boldsymbol{L}$ fraction with a significant reduction in $\mathbf{1}$, while maintaining options to also process the $S$ fraction for purifying 2 . The solvent selection was based on previously published reports and included (1) acetone, (2) hexane/toluene/ethanol (4:2:1; v:v:v) and (3) diethyl ether (Table 1) [6,9-11]. Crude soybean oil extract was dissolved in $500 \mathrm{ml}$ of each solvent and placed at $-80^{\circ} \mathrm{C}$ overnight. After removal from the freezer, the contents were immediately filtered using a Büchner funnel with sintered glass insert to yield an $\boldsymbol{L}$ and an $\boldsymbol{S}$ fractions (Figure 2). The solvent of the $\boldsymbol{L}$ fraction was evaporated, and the $S$ and dried $\boldsymbol{L}$ fractions separately dissolved in $10 \mathrm{ml}$ chloroform. At this stage, an aliquot from each fraction was analyzed by GC-MS [16]. The use of diethyl ether resulted in the most significant reduction of $\mathbf{1}$ in the $\boldsymbol{L}$ fraction (Table 1). Campesterol (3) was enriched but can be more easily removed using column chromatography [12-14]. None of the solvents were effective in differentially reducing the amounts of $\mathbf{1}$ in the $S$ fraction, while diethyl ether was the most appropriate solvent for maintaining high quantities of 2 (Table 1). All further experiments were thus performed using diethyl ether as a solvent. Phytosterols were distributed among the $\boldsymbol{S}$ and $\boldsymbol{L}$ fractions at $85 \%$ and 15\%, respectively (Figure 2).

The $\boldsymbol{S}$ and $\boldsymbol{L}$ fractions were then loaded separately onto silica gel columns, which were operated by gravity flow, and phytosterols eluted with hexane/ethyl acetate $(6: 1 ; \mathrm{v}: \mathrm{v})$ as eluent (Figure 2). The flow rate was adjusted to $1 \mathrm{ml} / \mathrm{min}$. Fractions $(10 \mathrm{ml})$ were recovered and constituents analyzed by GC-MS [16]. The elution order was 2, 1 and then 3. Fractions 18-30, which contained $\geq$ $70 \% \beta$-sitosterol, were pooled. The solvent of the combined $\beta$-sitosterol-enriched fractions was evaporated and the remainder dissolved in $200 \mathrm{ml}$ hexane. The phytosterol content was again determined by GC-MS [16] and indicated a yield of phytosterols of $30 \%$. The phytosterol mixture derived from the $S$ fraction, after silica gel

\section{Table 1 Purification of $\beta$-sitosterol (1) from crude soybean oil extract}

$\begin{array}{llll}\text { Purification } & \text { Fraction Stigmasterol } \beta \text {-Sitosterol Campesterol } \\ \text { step } & \end{array}$

step (1) (2)

[\% of total phytosterols]

Crude soybean oil extract (\$5753, Sigma-Aldrich)

$\begin{array}{llll}\text { n.a. } & 9.3 & 60.7 & 27.8\end{array}$

Fractional crystallization

$\begin{array}{lcccc}\text { Acetone } & \text { S } & 8.5 & 51.2 & 40.3 \\ & \mathbf{L} & 12.3 & 57.9 & 29.8 \\ \text { Hexane/toluene/ } & \mathbf{S} & 12.3 & 57.7 & 30.1 \\ \text { ethanol (4:2:1) } & \mathbf{L} & 4.5 & 66.0 & 29.5 \\ \text { Diethylether } & \mathbf{S} & 12.4 & 61.5 & 26.2 \\ & \mathbf{L} & 3.0 & 58.1 & 39.0\end{array}$

Silica column chromatography

$\begin{array}{llll}\boldsymbol{S} & 7.1 & 78.2 & 14.7 \\ \boldsymbol{L} & 1.5 & 82.0 & 16.5\end{array}$

Na-Y zeolite chromatography

$\begin{array}{llll}\boldsymbol{S} & 4.1 & 92.2 & 3.7 \\ \boldsymbol{L} & 0.1 & 94.2 & 5.7\end{array}$

Values represent averages of replicated experiments $(n=3-5)$. 


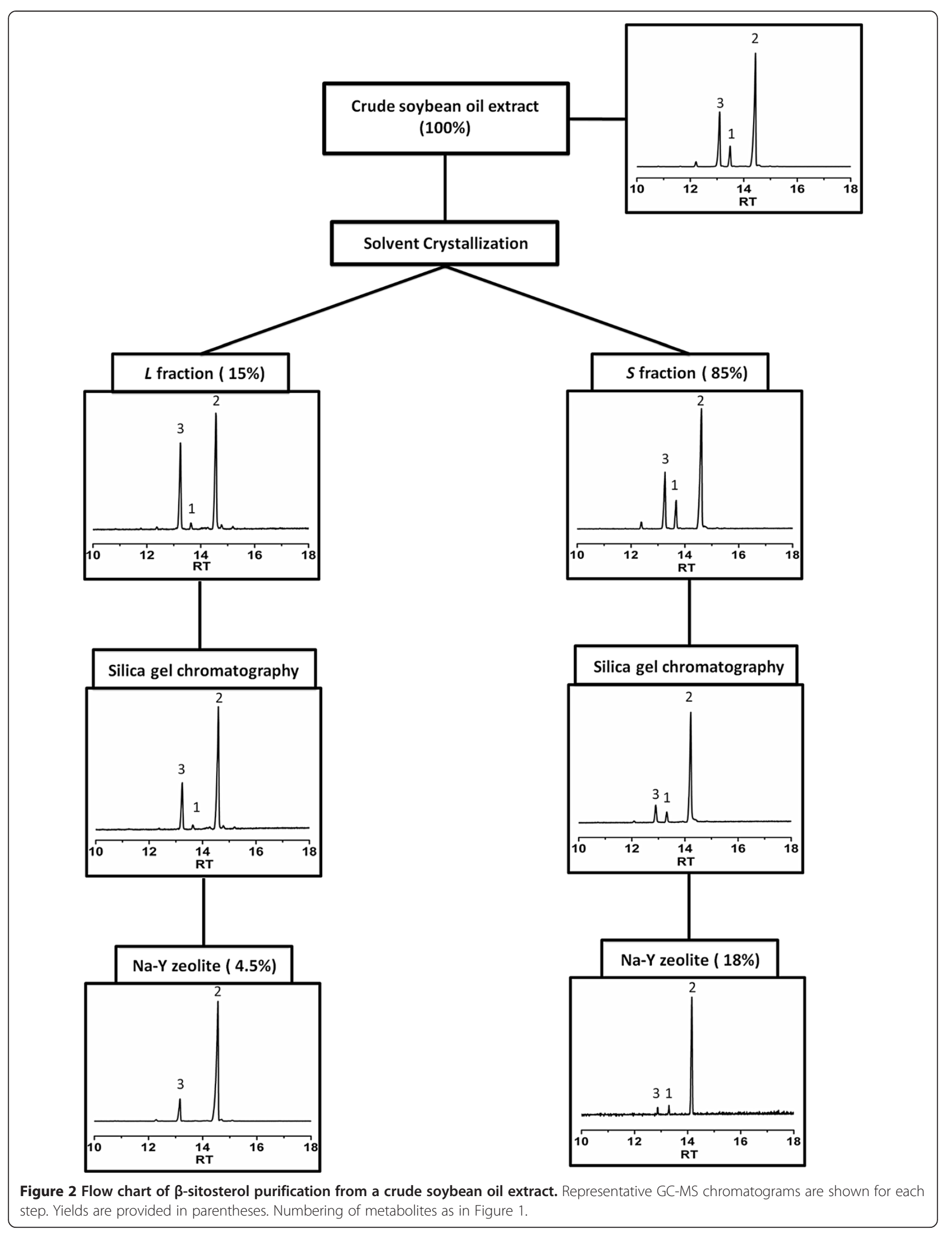


chromatography, contained a significantly increased proportion of $\mathbf{2}(78.2 \%)$, with decreased amounts of $\mathbf{1}$ and $\mathbf{3}$ (7.1\% and $14.7 \%$, respectively) (Table 1 ). The silica gelpurified phytosterol mixture from the processed $\boldsymbol{L}$ fraction contained even higher amounts of $2(82.0 \%)$ and a particularly low amount of $\mathbf{1}(1.5 \%)$. Previous attempts to further purify 2 employed multiple (8 to 10) cycles of silica gel chromatography [14]. Since this protocol is very time-consuming, we evaluated if the purification could be sped up by employing only one more purification step but with a different stationary phase.

Prior work using $\mathrm{Na}-\mathrm{Y}$ zeolite involved large amounts of material (60:1, w:w; adjusted based on total phytosterol amount) $[14,15]$. This method also required a high torque mixer and several manual sample loadings (multiple cycles). We lowered the activated $\mathrm{Na}-\mathrm{Y}$ zeolite amount to $10: 1(\mathrm{w}: \mathrm{w})$ and performed only a one-step purification with phytosterol extracts retrieved after silica gel chromatography ( $S$ and $\boldsymbol{L}$ fractions processed separately). The mixture was stirred at $200 \mathrm{rpm}$ at $32^{\circ} \mathrm{C}$ for $48 \mathrm{~h}$ (Figure 2). The zeolite was filtered off and the solvent of the filtrate removed in vacuo. The sterol composition was assessed by GC-MS [16]. The target metabolite 2 was obtained with high purity from both the $\boldsymbol{L}$ (94.2\%) and $S$ (92.2\%) fractions (Table 1). The overall yield of 2, when both the $S$ and $\boldsymbol{L}$ fractions were processed, was $22.5 \%$, which is a significant increase over the status quo, where the $\boldsymbol{L}$ fraction yields roughly $13 \%$ of the target metabolite [12-15]. The selectivity of $\mathrm{Na}-\mathrm{Y}$ zeolite for removing 3 is quite remarkable. In this microporous chromatographic material, $\mathrm{SiO}_{4}$ and $\mathrm{Al}_{2} \mathrm{O}_{3}$ tetrahedrae form pores with a uniform diameter of 7.4 $\AA$. Molecular modeling studies by Berezin and colleagues [12] indicated that 3 has a diameter of $6.3 \AA$, which allows its entry into the pores. In contrast, 1 and 2 have slightly larger diameters of 7.7 and $7.5 \AA$, respectively, which is too large for uptake, and these compounds therefore remain in solution.

In conclusion, we have demonstrated that, using a combination of fractional crystallization, silica gel and $\mathrm{Na}-\mathrm{Y}$ zeolite chromatography, the purification of $\mathbf{2}$ at high purity from a crude vegetable oil extract can be completed in $72 \mathrm{~h}$ with high overall yield. Considering the demand of $\mathbf{2}$ for clinical trials and biological structure-function studies, this protocol allows for the rapid production of the highly pure metabolite at an affordable price.

\section{Authors' contributions}

NS and BML designed the experiments and wrote the manuscript. NS and DH carried out the experiments. All authors read and approved the final manuscript.

\section{Acknowledgements}

This work was supported by a grant from the National Science Foundation (award number 0920758 to BML).

\section{Received: 13 November 2013 Accepted: 24 March 2014}

Published: 27 March 2014

\section{References}

1. Schaller $\mathrm{H}$ : New aspects of sterol biosynthesis in growth and development of higher plants. Plant Physiol Biochem 2004, 42:465-476.

2. Gendron JM, Wang ZY: Multiple mechanisms modulate brassinosteroid signaling. Curr Opin Plant Biol 2007, 10:436-441.

3. Lindsey K, Pullen ML, Topping JF: Importance of plant sterols in pattern formation and hormone signalling. Trends Plant Sci 2003, 8:521-525.

4. Ostlund RE Jr: Phytosterols in human nutrition. Annu Rev Nutr 2002, 22:533-549.

5. Kritchevsky D, Chen SC: Phytosterols - health benefits and potential concerns: a review. Nutr Res 2005, 25:413-428.

6. Kircher HW, Rosenstein FU: Purification of Sitosterol. Lipids 1973, 8:97-100

7. McCarthy FO, Chopra J, Ford A, Hogan SA, Kerry JP, O'Brien NM, Ryan E, Maguire AR: Synthesis, isolation and characterisation of beta-sitosterol and beta-sitosterol oxide derivatives. Org Biomol Chem 2005, 3:3059-3065.

8. Hang J, Dussault P: A concise synthesis of beta-sitosterol and other phytosterols. Steroids 2010, 75:879-883.

9. Clark JP, Lake F, Demars JA, Wilson GG: Purification of sterols by distillation. US Patent No 1975, 3:879,431.

10. Koskenniska LA: Process for the isolation of beta-sitosterol. US Patent No 1981, 4:298,974.

11. Xu WL, Huang YB, Qian JH, Sha O, Wang YQ: Separation and purification of stigmasterol and beta-sitosterol from phytosterol mixtures by solvent crystallization method. Sep Purif Technol 2005, 41:173-178.

12. Berezin MY, Dzenitis JM, Hughes BM, Ho SV: Separation of sterols using zeolites. Phys Chem Chem Phys 2001, 3:2184-2189.

13. Hyde PM, Elliot WH: Separation of sitosterol and campesterol on hydrophobic hydroxyalkyl sephadex LH-20. J Chromatogr 1972, 67:170-172

14. Zhang X, Geoffroy P, Miesch M, Julien-David D, Raul F, Aoude-Werner D, Marchioni E: Gram-scale chromatographic purification of beta-sitosterol. Synthesis and characterization of beta-sitosterol oxides. Steroids 2005, 70:886-895.

15. Chuang YH, Ju YH, Widjaja A: Separation of campesterol and beta-sitosterol from a sterol mixture. Separ Sci Technol 2006, 41:3027-3038.

16. Quanbeck SM, Brachova L, Campbell AA, Guan X, Perera A, He K, Rhee SY, Bais P, Dickerson JA, Dixon P, Wohlgemuth G, Fiehn O, Barkan L, Lange I, Lange BM, Lee I, Cortes D, Salazar C, Shuman J, Shulaev V, Huhman DV, Sumner LW, Roth MR, Welti R, llarslan H, Wurtele ES, Nikolau BJ: Metabolomics as a hypothesis-generating functional genomics tool for the annotation of arabidopsis thaliana genes of "Unknown Function". Front Plant Sci 2012, 3:15.

\section{doi:10.1186/1756-0500-7-182}

Cite this article as: Srividya et al:: Rapid purification of gram quantities of $\beta$-sitosterol from a commercial phytosterol mixture. BMC Research Notes 2014 7:182.

\author{
Abbreviations \\ S: Solid fraction; L: Liquid fraction; GC-MS: Gas chromatography-mass \\ spectrometry.
}

